\title{
REDUÇÃO DO CONSUMO ENERGÉTICO DO PROCESSO DE DESTILAÇÃO
}

\author{
R. M. L. OLIVEIRA ${ }^{1}$, C. V. ARAÚJO ${ }^{2}$ e R. P. BRITO ${ }^{3}$ \\ ${ }^{1}$ Universidade Federal de Campina Grande, Departamento de Engenharia Química. \\ ${ }^{2}$ Universidade Federal de Campina Grande, Departamento de Engenharia Química. \\ ${ }^{3}$ Universidade Federal de Campina Grande, Departamento de Engenharia Química, Prof. Dr.
}

\begin{abstract}
RESUMO - A principal motivação para pesquisas sobre o processo de destilação surge a partir do fato das colunas de destilação usarem grandes quantidades de energia, devido à necessidade de repetidas vaporizações e condensações. Um procedimento para redução do consumo energético é o pré-aquecimento da alimentação, com energia recuperada do produto de base. Uma variante desta alternativa é dividir a alimentação em duas correntes de mesma composição e diferentes condições térmicas, sendo uma totalmente vaporizada, alimentando a base da coluna. Neste trabalho, foi utilizado o simulador de processos Aspen para simulações em um vaso flash e em uma coluna flash. O sistema escolhido para avaliação de tal procedimento foi o benzeno-tolueno-xileno em regimes estacionário e transiente de modo que se torna possível a análise do sistema em termos de separação e performance de controle.
\end{abstract}

\section{INTRODUÇÃO}

A destilação é um dos mais antigos e importantes processos de separação utilizados na indústria química/petroquímica. A literatura refere-se à destilação como sendo "o processo de separação em relação ao qual todos os outros devem ser comparados" (KISTER, 1992; KUNESH et al., 1995). De acordo com Humphrey (1995), somente nos Estados Unidos existiam cerca de 40.000 colunas de destilação em operação, as quais respondiam por mais de $90 \%$ dos processos de separação e investimento da ordem de U\$\$ 8 bilhões. Diante de tais dados, surge a necessidade de novas pesquisas que possibilitem o melhor aproveitamento da energia utilizada em colunas de destilação.

A fim de reduzir ou melhor utilizar a carga térmica dos trocadores de calor que antecedem as colunas de destilação, propõe-se modificar a topologia de alimentação da mesma como proposto por Wankat e Kessler (1993), dividindo-se a alimentação em duas correntes, de mesma composição, porém diferentes entalpias. Isso pode resultar em uma redução do número de estágios, atingindo-se uma mesma separação, considerando-se a mesma razão de refluxo, ou ainda, reduzindo a razão de refluxo para o mesmo número de estágios, ao se comparar uma coluna convencional à coluna com a nova topologia. 


\section{DESCRIÇÃO DO PROBLEMA}

Segundo Henley e Seader (1988), usualmente o grande consumo de energia envolvido em processos de separação está associado a compressores, refervedores e condensadores. Desta forma, a procura por alternativas de novas configurações dos processos de separação que aumentem a eficiência do consumo de energia é de extrema importância.

Wankat e Kessler (1993) propuseram dividir a alimentação em duas partes, modificando a entalpia (condição térmica) de apenas uma das partes, vaporizando-se completamente uma delas. Eles observaram que no caso das colunas completas o número de estágios necessários para realizar determinada separação diminui quando comparado com a configuração convencional. Uma importante observação citada neste trabalho é a redução da razão de refluxo para a configuração com duas alimentações, caso seja utilizado o mesmo número de estágios.

Sabendo-se que a análise dinâmica deste tipo de topologia ainda não foi explorada, este trabalho tem como objetivo geral a comparação do comportamento dinâmico para as topologias mostradas nas Figuras 1 e 2, bem como propor sistemas de controle e analisar a performance destes.

\section{METODOLOGIA E ESTRATÉGIA DE SIMULAÇÃO}

O vaso flash (Figura 1) foi simulado usando a rotina Flash2 do Aspen Plus, o qual realiza um cálculo flash (ELV) rigoroso. A coluna flash (Figura 2) foi simulada usando a rotina RadFrac do Aspen Plus, com a eficiência de cada prato mantida fixa em 100\%, e consiste em uma configuração em que não há condensador nem refervedor, fazendo com que o grau de liberdade desta seja zero, portanto não é necessário especificar dados além do número de estágios, estágios de alimentação e perfil de pressão ao longo da coluna.

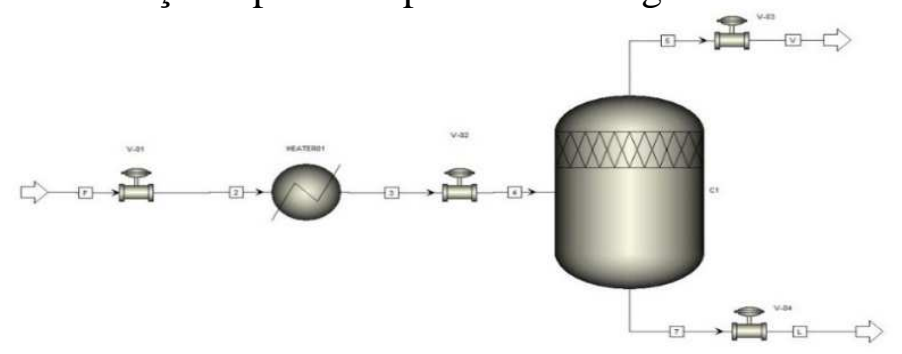

Figura 1 - Fluxograma de processo de destilação em um vaso flash em regime estacionário.

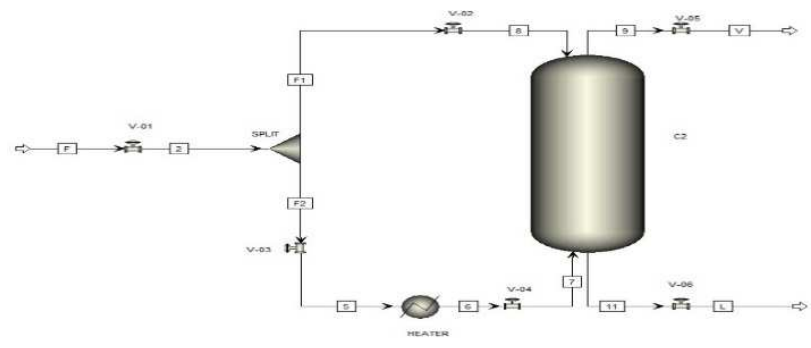

Figura 2 - Fluxograma de processo de destilação em uma coluna flash em regime estacionário. 
Para a configuração da coluna flash, as alimentações líquida e vapor foram realizadas no topo e na base, respectivamente. E ainda, avaliou-se o efeito do número de estágios da coluna, para 5 e 10 estágios de equilíbrio.

O equilíbrio líquido vapor foi (VLE) foi calculado através da hipótese de que a fase vapor constitui-se de um gás ideal e a fase líquida de uma solução ideal, sendo possível adotar o modelo termodinâmico ideal.

Para os trocadores de calor que antecedem o vaso flash e a coluna flash, as frações vaporizada foram fixadas em 0,5 e 1 , respectivamente.

Foram incluídas válvulas no processo para considerar a influência de um equipamento sobre o outro a qual esteja conectado de modo que a simulação em estacionário no Aspen Plus fosse exportada para o estado transiente, Aspen Dynamics, utilizando o modo Pressure Driven.

Foram adicionados ao vaso flash controladores de vazão de alimentação e de temperatura do vaso flash, aquele através da válvula na corrente de alimentação e este, pela carga térmica do trocador de calor que antecede o vaso flash, sendo ambos de ação reversa; e para coluna flash, além deste dois controladores foi adicionado um controlador de vazão de alimentação de líquido saturado que atua como refluxo na coluna.

As Figuras 3 e 4 apresentam os fluxograma utilizados em regime transiente em Aspen Dynamics.

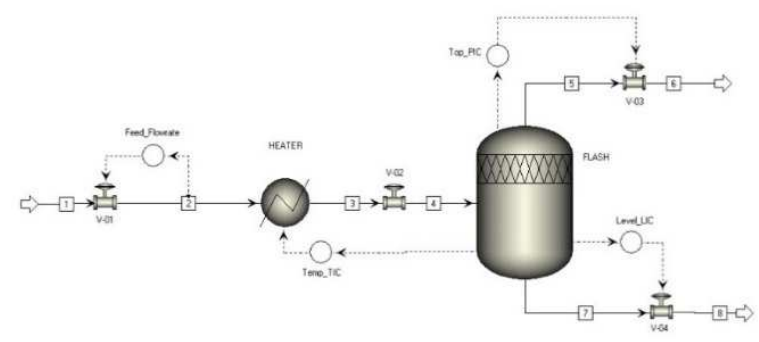

Figura 3 - Esquema do vaso flash utilizado no regime transiente.

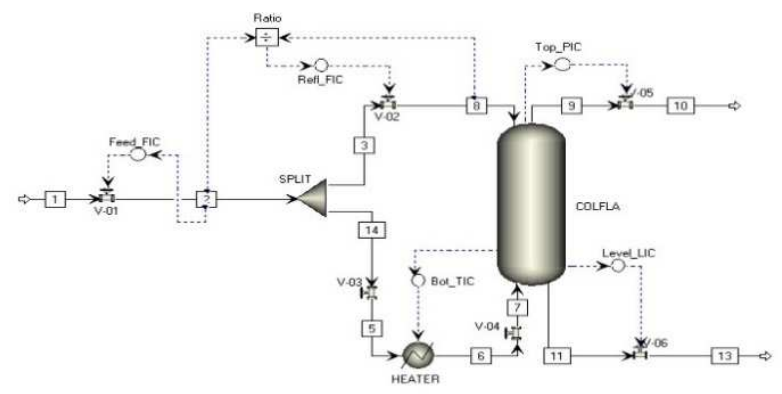

Figura 4 - Esquema da coluna flash utilizada em regime transiente.

No modelo em estado estacionário foi realizada a análise de sensibilidade, em que foi usada a ferramenta Sensitivity do Aspen Plus, de algumas variáveis para o caso de haver aumento na fração vaporizada do trocador de calor no caso do vaso flash e para aumento na fração de divisão do separador no caso da coluna flash.

Em regime transiente foram realizadas perturbações positivas e negativas do tipo degrau de amplitude $20 \%$ em relação ao set point, com objetivo de analisar não só o comportamento da separação obtida, como também outras variáveis que influenciam nesta. Os distúrbios na vazão de alimentação foram realizados como mostra a Figura 5, em que observa-se 
primeiramente o aumento de $20 \%$ desta, logo após estabilizar tem-se o retorno para o set point e ainda, a redução de $20 \%$, seguida da volta ao set point.

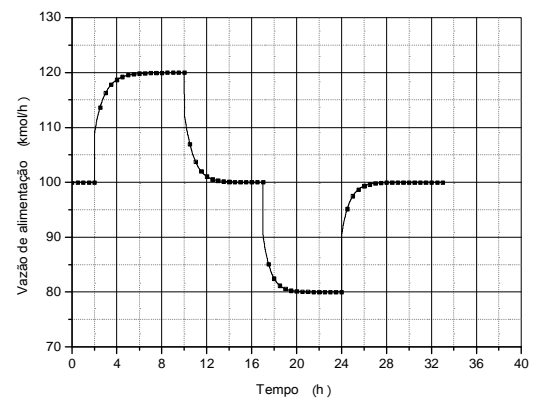

Figura 5 - Distúrbios de $-20 \%$ e $+20 \%$ na vazão de alimentação para o vaso flash e coluna flash.

A resposta da variável controlada foi avaliada para sistemas em malha aberta e malha fechada, sendo aquela aberta no controle de temperatura no vaso flash e na coluna flash e da razão de refluxo para a coluna flash.

\section{RESULTADOS E DISCUSSÕES}

\subsection{Regime Estacionário}

Vaso Flash: $\mathrm{O}$ aumento da fração vaporizada no trocador de calor que antecede o vaso flash provoca uma redução na composição de benzeno na corrente de saída de topo, como mostra a Figura 6a, pois esta mudança altera as condições de ponto de bolha deste e ainda favorece a vaporização dos componentes menos voláteis (tolueno e xileno). A vazão do destilado aumenta com tal mudança (Figura 6b), já que uma maior quantidade de alimentação será vaporizada, porém, isso não é favorável à separação visto que há uma maior composição dos componentes mais pesados na corrente de topo.

Com o aumento da fração vaporizada, há um aumento na carga térmica do trocador de calor e na temperatura de equilíbrio do vaso flash. Este último fato reflete diretamente na eficiência de separação, a qual é reduzida, como é verificado na Figura 6c.

É importante observar que o aumento da fração vaporizada faz com que a temperatura do vaso se aproxime da temperatura do componente menos volátil (xileno).

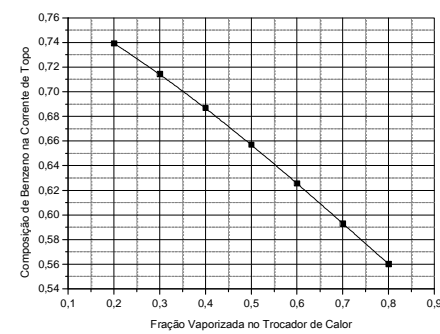

(a)

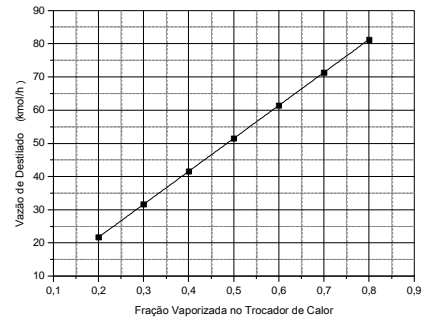

(b)

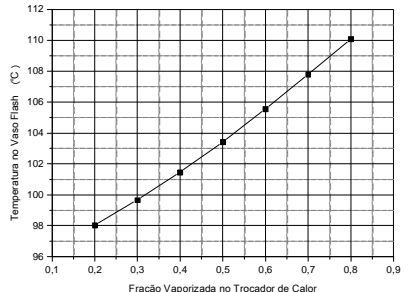

(c)

Figura 6 - Efeito da fração vaporizada (a) na composição de benzeno no topo para o vaso flash; (b) na vazão de destilado para o vaso flash; (c) na temperatura do vaso flash. 
Coluna Flash: Como a coluna flash possui uma das alimentações de vapor saturado, o que significa que este não pode ser alterado, foi realizada uma análise de sensibilidade para algumas variáveis com o aumento na fração de divisão do separador $(q)$, o que define a quantidade de líquido e vapor saturados que alimentam a coluna. Este procedimento foi realizado para colunas com 5 e 10 estágios.

Com o aumento de $q$, verificou-se que há, como no vaso flash, uma redução da composição de benzeno no topo da coluna (Figura 7a), pois a vaporização dos componentes menos voláteis é favorecida, aumentando as temperaturas de topo e de base da coluna (Figuras $7 \mathrm{~b}$ e $7 \mathrm{c}$ ), influenciando diretamente na separação. A redução na composição acontece gradativamente e ainda há uma maior resistência para alguns valores altos de $q$.

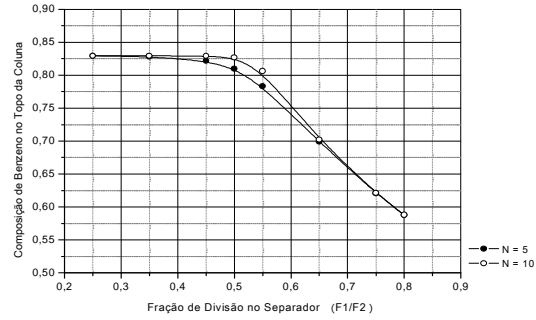

(a)

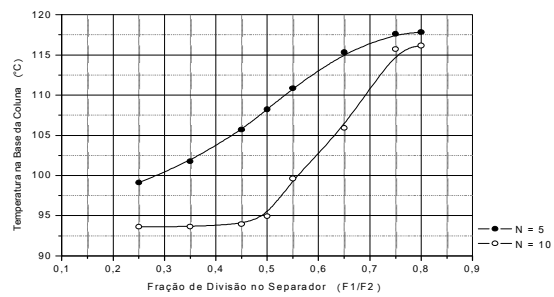

(c)

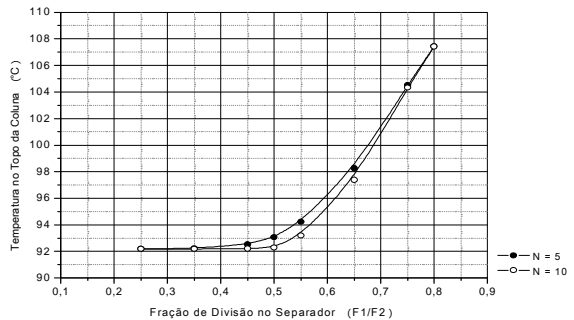

(b)

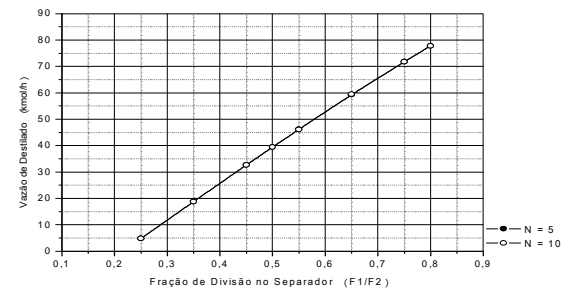

(d)

Figura 7 - Efeito da fração de divisão no separador para a coluna flash com 5 e 10 estágios.

(a) composição de benzeno no topo; (b) temperatura de topo (c) temperatura da base; (d) vazão de destilado.

Pode-se observar que na coluna com dez estágios, a máxima separação e as temperaturas de topo e de base permanecem inalteradas para altos valores de $q$, resultando em maior produtividade, devido ao aumento na vazão de vapor em ambos os casos, para cinco e dez estágios (Figura 7d), oferecendo maior flexibilidade operacional em caso de haver variação na disponibilidade de carga térmica para o trocador que antecede a coluna.

A Figura 8 apresenta uma comparação entre o vaso flash e a coluna flash quanto à quantidade de energia consumida no trocador de calor. O vaso flash requer sempre uma maior quantidade de carga térmica do trocador de calor que a coluna, apresentando mais uma vantagem para o uso da configuração flash. 


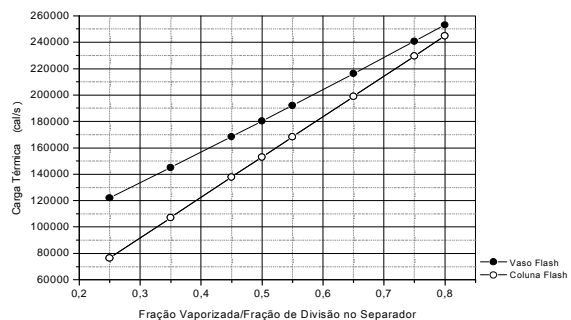

Figura 8 - Efeito da fração vaporizada para o vaso flash e fração de divisão do separador para a coluna flash na carga térmica do trocador de calor.

\subsection{Regime Transiente}

Vaso Flash: Para o sistema de controle em malha aberta, pode-se verificar que houve aumento na composição de benzeno no topo do vaso flash, devido à redução de temperatura de equilíbrio que ocorre com o aumento da vazão de alimentação, o que favorece a vaporização, apenas, do componente mais volátil que, neste caso, é o benzeno. Observa-se ainda na Figura 8a que sistema de controle não requer muito tempo até que a variável volte a estabilizar, porém esta estabilização não ocorre no valor desejado, set point.

Por outro lado, para o controle em malha fechada, constata-se o mesmo aumento que aquele verificado no controle em malha aberta para a composição de benzeno no topo do vaso flash, porém, observa-se que há a estabilização desta variável no set point, apesar de que o sistema de controle requer mais tempo para que isso aconteça, como apresenta a Figura 9b.

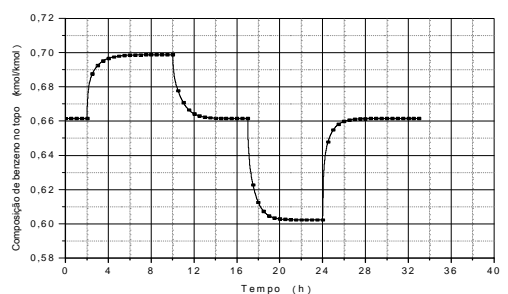

(a)

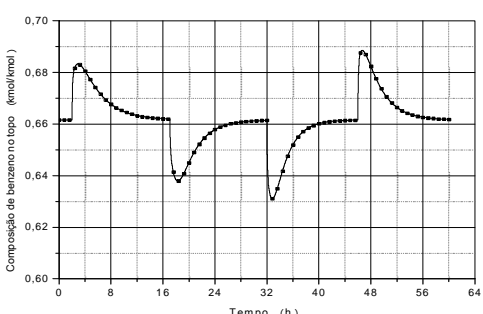

(b)

Figura 9 - Comportamento da composição de benzeno no topo do vaso flash (a) em malha aberta; (b) em malha fechada.

As Figuras 10a e 10b apresentam o comportamento da temperatura de equilíbrio do vaso flash para o sistema de controle em malha aberta e em malha fechada, respectivamente.

A variação de temperatura de equilíbrio pode ser justificada pela variação na fração vaporizada do trocador de calor, visto que esta variável é inversamente proporcional a vazão de alimentação e ainda determina a quantidade de vapor que entra no vaso flash, o que faz com que a vazão de destilado sofra variações proporcionais a esta.

A carga térmica do trocador de calor que antecede o vaso flash irá sofrer variações conforme aquelas observadas na temperatura de equilíbrio, visto que aquela é a variável manipulada reversamente no controle desta. 


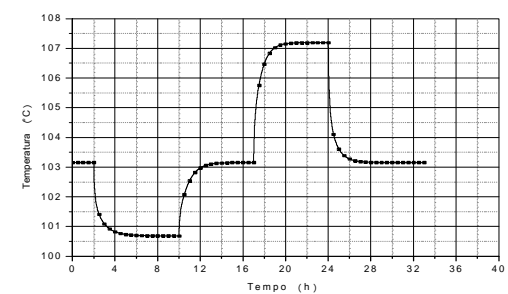

(a)

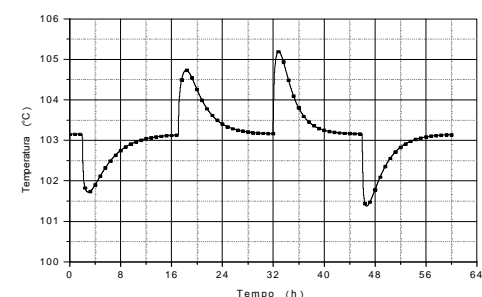

(b)

Figura 10 - Comportamento da temperatura de equilíbrio do vaso flash (a) em malha aberta;

(b) em malha fechada.

Coluna Flash: De modo análogo ao que foi realizado para o vaso flash, os sistemas de controle em malha aberta e malha fechada foram analisados para a coluna flash, ressaltando para o sistema de controle em malha aberta estava em manual não só o controle de temperatura da base da coluna como também o controle de razão de refluxo dado pela razão entre a vazão de alimentação e a vazão de alimentação de líquido saturado.

Os distúrbios foram realizados de modo análogo ao da Figura 5.

Para a composição de benzeno no topo da coluna, como apresentam as Figuras 8a e 8b, pode-se observar que esta irá sofrer variações quando ocorre distúrbio negativo na vazão de alimentação (-20\%), para o sistema de controle em malha aberta, e para o sistema de controle em malha fechada esta variável não sofre variações significativas, o que pode ser explicado pelo comportamento da temperatura no topo da coluna em ambos os casos, como mostram as Figuras 11a e 11b.

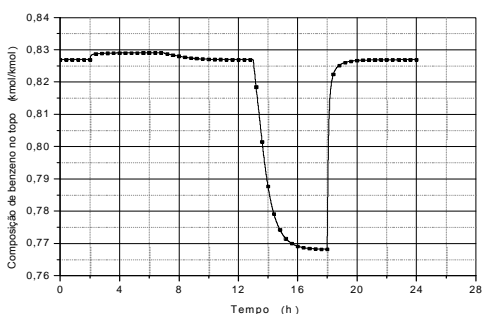

(a)

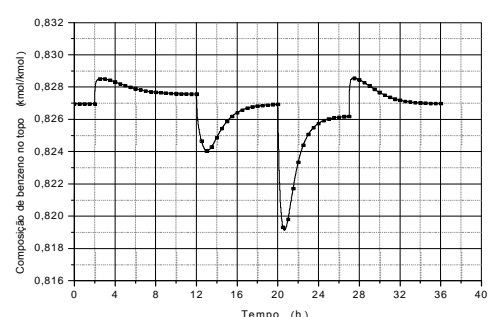

(b)

Figura 11 - Comportamento da composição de benzeno no topo da coluna flash (a) em malha aberta; (b) em malha fechada.

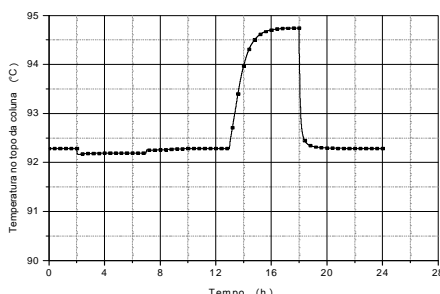

(a)

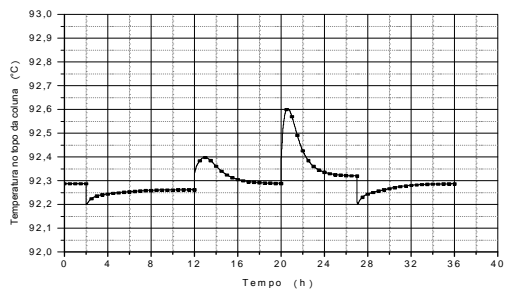

(b)

Figura 12 - Comportamento da temperatura no topo da coluna flash (a) em malha aberta; (b) em malha fechada. 
A carga térmica, como discutido para o vaso flash, sofrerá alterações conforme a necessidade de aumentar ou reduzir a temperatura na base da coluna, atuando de modo reverso.

A razão de refluxo (alimentação de líquido saturado) varia conforme a vazão de alimentação visto que esta é dada pela razão entre a vazão de alimentação e a vazão de alimentação de líquido saturado. E ainda, esta variável tem influência sobre a vazão de destilado, visto que maior quantidade de refluxo interno dado pela maior quantidade de vazão de alimentação, significa maior quantidade de líquido saturado entrando no primeiro estágio, alterando as condições de equilíbrio deste.

\section{CONCLUSÃO}

Para o regime estacionário, verifica-se que o aumento da fração vaporizada no vaso flash e o aumento da fração de divisão do separador $(q)$ provoca não só a redução na composição de benzeno no topo, em ambos os casos, como também o aumento da carga térmica do trocador de calor, o que não é favorável para o processo. Ao comparar os resultados dos fluxogramas, vaso flash e coluna flash, observou-se que esta apresenta vantagens, visto que há pouca variação na composição de benzeno. A coluna com 10 estágios mantém a maior composição obtida para valores altos de $q$, apresentando maior produtividade, havendo aumento também na vazão de destilado. Verifica-se ainda que a coluna flash requer menor quantidade de calor e possui maior eficiência na separação.

No regime transiente, tanto para o vaso flash quanto para a coluna flash, no sistema de controle em malha aberta, apesar de chegar a estabilização em menor tempo quando se provoca um distúrbio, o valor da variável controlada não volta ao set point. Por outro lado, o sistema de controle em malha fechada faz com que os valores das variáveis de processo retornem ao valor desejado.

Portanto, o sistema de controle em malha fechada foi satisfatório em ambos os casos, visto que o efeito de realimentação da variável de processo permite que este tome ações corretivas de maneira mais eficiente.

\section{REFERÊNCIAS BIBLIOGRÁFICAS}

HUMPHREY, J. (1995) Separation Processes: Playing a Critical Role. Chem. Eng. Progr, 91, 10 .

KISTER, H.Z. Distillaion Design. McGraw-Hill, Inc. (1992).

WANKAT, P. C. e KESSLER, D. P. (1993) Two-Feed Distillation: Same Composition Feeds With Different Enthalpies, Ind. Chem. Res., vol. 32, 3061-3067. 